\title{
Increased Sensitivity to Agonist-Induced Seizures, Straub Tail, and Hippocampal Theta Rhythm in Knock-In Mice Carrying Hypersensitive $\alpha 4$ Nicotinic Receptors
}

\author{
Carlos Fonck, ${ }^{1}$ Raad Nashmi, ${ }^{1}$ Purnima Deshpande, ${ }^{1}$ M. Imad Damaj, ${ }^{2}$ Michael J. Marks, ${ }^{3}$ Anett Riedel, ${ }^{4}$ \\ Johannes Schwarz, ${ }^{1,4}$ Allan C. Collins, ${ }^{3}$ Cesar Labarca, ${ }^{1}$ and Henry A. Lester ${ }^{1}$ \\ ${ }^{1}$ Division of Biology, California Institute of Technology, Pasadena, California 91125, ${ }^{2}$ Department of Pharmacology and Toxicology, Medical College of \\ Virginia Campus/Virginia Commonwealth University, Richmond, Virginia 23298, ${ }^{3}$ Institute for Behavioral Genetics, University of Colorado, Boulder, \\ Colorado 80309, and ${ }^{4}$ Department of Neurology, University of Leipzig, Leipzig, Germany 04103
}

\begin{abstract}
We studied a strain of exon replacement mice ("L9'S knock-in") whose $\alpha 4$ nicotinic receptor subunits have a leucine to serine mutation in the M2 region, 9' position (Labarca et al., 2001); this mutation renders $\alpha 4$-containing receptors hypersensitive to agonists. Nicotine induced seizures at concentrations $(1 \mathrm{mg} / \mathrm{kg})$ approximately eight times lower in L9'S than in wild-type (WT) littermates. At these concentrations, L9'S but not WT showed increases in EEG amplitude and theta rhythm. L9'S mice also showed higher seizure sensitivity to the nicotinic agonist epibatidine, but not to the $\mathrm{GABA}_{\mathrm{A}}$ receptor blocker and proconvulsant bicuculline. Dorsiflexion of the tail (Straub tail) was the most sensitive nicotine effect found in $\mathrm{L}^{\prime} \mathrm{S}$ mice $(0.1 \mathrm{mg} / \mathrm{kg})$. The $\mathrm{L} 9^{\prime} \mathrm{S}$ mice were hypersensitive to galanthamine- and tacrine-induced seizures and Straub tails. There were no apparent neuroanatomical differences between L9'S and WT mice in several brain regions. [ $\left.{ }^{125} \mathrm{I}\right]$ Epibatidine binding to brain membranes showed that the mutant allele was expressed at $\sim 25 \%$ of WT levels, presumably because of the presence of a neomycin selection cassette in a nearby intron. ${ }^{86} \mathrm{Rb}$ efflux experiments on brain synaptosomes showed an increased fraction of function at low agonist concentrations in L9'S mice. These data support the possible involvement of gain-of-function $\alpha 4$ receptors in autosomal dominant nocturnal frontal-lobe epilepsy.
\end{abstract}

Key words: nicotinic receptor; ADNFLE; seizure; epilepsy; cholinergic; gain of function; knock-in; mouse

\section{Introduction}

Nicotine, the addictive component of tobacco, elicits a wide range of behavioral effects when administered to rodents (Brioni et al., 1997). Increasing doses of nicotine in mice can cause sedation, decrease nociception, alter memory and learning, decrease body temperature, and at high concentrations, induce clonictonic seizures and death. It is not known what roles the various individual nicotinic receptor types expressed in the mammalian CNS play in the different nicotine-induced responses. In terms of its sensitivity to agonist, abundance, and widespread distribution in the brain, perhaps the most important nicotinic receptor subtype is the one formed by $\alpha 4$ coassembled with $\beta 2$ subunits. Expression in heterologous systems has shown that $\alpha 4 \beta 2$ receptors have higher sensitivity to nicotine than $\alpha 7, \alpha 2 \beta 2, \alpha 3 \beta 2$, $\alpha 3 \beta 4$, or $\alpha 4 \beta 2 \alpha 5$ receptors (Wonnacott, 1997). $\alpha 4$ and $\beta 2$ nicotinic subunits are abundantly found in the neocortex, hippocampus, septum, thalamus, midbrain, and brainstem (Wada et al., 1989).

To further understand the function of $\alpha 4$-containing nico-

Received Sept. 17, 2002; revised Dec. 24, 2002; accepted Jan. 13, 2003.

This work was supported by the Tobacco-Related Disease Research Program; by the Keck Foundation; by National Institutes of Health Grants NS-117656, MH-49176, DA-10156, and DA-11836; and by a National Research Service Award to C.F. We thank Jim Boulter, Bruce Cohen, Bonnie Davis, Ken Davis, Sharon Grady, Margaret Jacobs, Yuan Liu, and Jeanne Wehner for discussion; Sarah McCallum for experiments on GABA release; Istvan Mody and Enric Claverol for teaching us electroencephalography; and Bronagh Glaser for administrative assistance.

Correspondence should be addressed to Henry A. Lester, 156-29 Caltech, Pasadena, CA 91125. E-mail: lester@caltech.edu.

Copyright $\odot 2003$ Society for Neuroscience $\quad 0270-6474 / 03 / 232582-09 \$ 15.00 / 0$ tinic receptors in the brain, we have created a knock-in mouse line expressing a hypersensitive $\alpha 4$-containing receptor. Selection and design of the $\alpha 4$ leucine to serine mutation in the M2 pore lining region at position $9^{\prime}$ (L9'S) was based on previous heterologous expression studies: when this conserved leucine was mutated to serine, there were major increases in agonist sensitivity (Revah et al., 1991; Labarca et al., 1995). Homozygous L9'S animals containing a neomycin-selection cassette ("neo-intact") and heterozygous L9'S animals without the cassette ("neodeleted") die soon after birth. However, neo-intact heterozygous L9'S mice have reduced expression of the hypersensitive receptor, are fertile, and display increased anxiety (Labarca et al., 2001) (these gene dose effects are discussed in Fig. 8, below). We report now on the effect of this gain-of-function mutation in L9'S mice on seizure and Straub tail responses.

Seizure studies on $\alpha 4$-mutated mice are particularly relevant for epilepsy research, because all known mutations responsible for autosomal dominant nocturnal frontal lobe epilepsy (ADNFLE) occur in the M2 region of $\alpha 4$ or $\beta 2$ subunits (for review, see Sutor and Zolles, 2001). ADNFLE is a rare form of epilepsy that consists of frequent, brief, and sometimes violent seizures, starting during childhood, originating in frontal cortex and occurring during sleep. Thus far, and based only on heterologous expression experiments, there is disagreement as to whether ADNFLE mutations result in gain or loss of receptor function (Kuryatov et al., 1997; Figl et al., 1998; Bertrand et al., 2002). As of mid-2002, five different missense mutations in the M2 regions of the $\alpha 4 \beta 2$ nicotinic acetylcholine receptor (nAChR) are known 
that cause ADNFLE. Therefore we assessed the L9'S mice for sensitivity to nicotinic seizures, and we report a dramatic hypersensitivity.

\section{Materials and Methods}

Mice. Generation of the L' 9 'S strain, by replacing the native $\alpha 4$ subunit of the nAChR with a mutated form, has been described previously (Labarca et al., 2001). Male and female mice heterozygous for the L9'S mutation and their wild-type (WT) littermates were used for behavioral, in vivo electrophysiological, neuroanatomical and neurochemical studies. Experiments were performed according to National Institutes of Health and local institutional guidelines for the humane treatment of laboratory animals. Mice that appeared to be in extreme and/or prolonged pain were killed.

Behavioral responses. Mice were placed in the behavior room $4 \mathrm{~d}$ before experiments and were maintained on a $12 \mathrm{hr}$ light/dark cycle with ad libitum access to food and water. Acute behavioral responses to nicotine, mecamylamine, epibatidine, bicuculline, galanthamine, tacrine, morphine sulfate, and naloxone were determined in L9'S and WT mice. Unless specified, drugs and chemicals used in these studies were obtained from Sigma (St. Louis, MO). Galanthamine and tacrine were purchased from Tocris (Ellisville, MO). Drugs were dissolved in saline, and concentrations were adjusted so that total volume injected was $10 \mu \mathrm{l} / \mathrm{gm}$ body weight. Initial dose and mode of administration (subcutaneous versus intraperitoneal) for each drug were based on reports in the literature. Animals injected with the various compounds were placed inside a Plexiglas cage $(30 \times 14 \mathrm{~cm})$, videotaped with a digital camcorder, and behaviorally scored by experimenters blind to their genotype. Mice were videotaped starting $1 \mathrm{~min}$ before and for 5-15 min after a single injection. Frequency, duration, and time of onset of the behavioral responses (seizure, Straub tail, sedation, circling, shaking) to each drug treatment were recorded and tabulated. Seizure intensity assessment was based on a recently developed scale (Franceschini et al., 2002).

In vivo electrophysiology. Simultaneous video-electroencephalographic recordings were obtained from free moving animals. Stereotaxic surgeries were performed on mice anesthetized with a ketamine (100 $\mathrm{mg} / \mathrm{kg})$ and xylazine $(25 \mathrm{mg} / \mathrm{kg})$ mixture using mouse atlas coordinates (Franklin and Paxinos, 1997). A pair of 0.1-mm-diameter tungsten wire electrodes $(\sim 200 \mathrm{k} \Omega$ AC impedance $)$ were inserted through a hole drilled in the cranium and placed stereotactically within the hippocampus ( $1.9 \mathrm{~mm}$ caudal to bregma, $1.4 \mathrm{~mm}$ lateral to midline, at a depth of $1.8 \mathrm{~mm}$ ). A ground screw electrode was placed into the contralateral side of the skull. A three pin connector (ground electrode plus two recording electrodes) was cemented to the skull surface with dental acrylic. After surgery, mice were allowed to recover for $48 \mathrm{hr}$. Electrophysiological recordings started $10 \mathrm{~min}$ before and continued for $15 \mathrm{~min}$ after a single nicotine injection of either 2 or $10 \mathrm{mg} / \mathrm{kg}$. Data were acquired with a differential amplifier (World Precision Instruments, Hamden, CT), using a sampling rate of $10 \mathrm{kHz}$ and bandpass filtered $(1-200 \mathrm{~Hz})$. Data analysis was performed with pClamp 8.2 software (Axon Instruments, Union City, CA). Changes in EEG activity attributable to nicotine were assessed by calculating SD and power spectra before and after nicotine injection. Power spectrum analysis used a Hamming transform on 150 sec of continuous data.

Neuroanatomy. Brain sections obtained from three WT and three L9'S adult mice were Nissl-stained. For histology, animals were deeply anesthetized by carbon dioxide inhalation and then perfused with saline containing $0.1 \%$ heparin, followed by $4 \%$ formaldehyde. Brains were dehydrated by successive ethanol washes $(50,70$, and $96 \%)$, brought into a mixture of diethyl ether and $100 \%$ ethanol (1:1), and embedded in celloidin. Frontal series of $50-\mu \mathrm{m}$-thick sections were cut on a sliding microtome (Reichert-Jung, Hamburg, Germany). Sections were stained in a heated $0.1 \%$ aqueous solution of toluidine blue (Merck, Darmstadt, Germany), washed in mild hydrochloric acid solution, and later transferred to $96 \%$ ethanol. Finally, sections were mounted onto slides, dehydrated with optal, bathed in xylene, and coverslipped with Canada balsam. Sections were examined with a Zeiss (Oberkochen, Germany) Axiophot microscope and digitized with an AxioCam HRc digital camera.
Epibatidine binding. [ $\left.{ }^{125} \mathrm{I}\right]$ Epibatidine binding was used for quantitating nicotinic receptor levels (Marks et al., 1998). The particulate fraction of brain homogenates was washed three times in hypotonic buffer at $12,000 \times g$ to obtain a purified membrane preparation. Incubations were performed in 96 well plates in $30 \mu$ l of binding buffer (in mM: $140 \mathrm{NaCl}$, $1.5 \mathrm{KCl}, 2 \mathrm{CaCl}_{2}, 1 \mathrm{MgSO}_{4}$, and $25 \mathrm{HEPES}, \mathrm{pH} 7.5$ ) for $2 \mathrm{hr}$ at $22^{\circ} \mathrm{C}$ using $200 \mathrm{pm}\left[{ }^{125} \mathrm{I}\right]$ Epibatidine. Cytisine was used to displace epibatidine counts thought primarily to reflect $\alpha 4 \beta 2$ receptors. Incubations were terminated by filtration into Gelman A/E glass fiber filters, followed by washes with ice-cold buffer. Inhibition curves were fitted to either one or two site models.

Synaptosomal studies. Thalamus taken from adult mice, which is a nicotinic receptor-rich region, were used for synaptosome preparation. After dissection, tissue was immediately placed in 10 vol of ice-cold isotonic sucrose buffered solution (5 mM HEPES) and homogenized by hand using a glass-Teflon tissue grinder. The supernatant was centrifuged at $12,000 \times g$ for $20 \mathrm{~min}$, and the resulting pellet was resuspended in an isotonic buffer to obtain fresh synaptosomes. For rubidium efflux experiments, loading of synaptosomes was achieved by incubation with 4 $\mu \mathrm{Ci}$ of carrier-free ${ }^{86} \mathrm{Rb}$ at $22^{\circ} \mathrm{C}$ for $30 \mathrm{~min}$ in loading buffer (in mM: 140 $\mathrm{NaCl}, 1.5 \mathrm{KCl}, 2 \mathrm{CaCl}_{2}, 1 \mathrm{MgSO}_{4}, 25 \mathrm{Na}$ HEPES, 20 glucose, $\mathrm{pH} 7.5$ ). During the final $5 \mathrm{~min}$ of uptake, $10 \mathrm{~mm}$ diisopropyl fluorophosphate was added to inhibit ACh esterase. After uptake, samples were filtered under gentle vacuum and washed with $0.5 \mathrm{ml}$ of loading buffer. Filters containing synaptosomes were transferred to a polypropylene platform and perfused with $135 \mathrm{~mm} \mathrm{NaCl}, 5 \mathrm{~mm} \mathrm{CsCl}, 1.5 \mathrm{~mm} \mathrm{KCl}, 2 \mathrm{~mm} \mathrm{CaCl}_{2}, 1$ mm $\mathrm{MgSO}_{4}, 0.1 \%$ BSA, 50 nм TTX, 20 mm glucose, and 25 mм HEPES, $\mathrm{pH}$ 7.5. Buffer was applied and removed with peristaltic pumps. The effluent passes through a $200 \mu$ l Cerenkov cell within a $\beta$ counter (IN/US Systems) that provides continuous online detection. Samples were stimulated for $5 \mathrm{sec}$ with ACh or nicotine by diverting buffer flow through a $200 \mu$ l loop. Responses were normalized to the basal efflux rate, which was fitted to a one or two component decay model.

Statistical analysis. Results were analyzed using Sigmastat, Origin, or Excel. Differences among means were considered significant when they were attributable to randomness with $\leq 5 \%$ chance. For data with $n \geq 6$, we verified normal distribution and random error distribution of the data.

\section{Results}

\section{Behavioral responses in hypersensitive knock-in mice}

L9'S mice were more sensitive to several effects of nicotine than their WT littermates (Fig. 1). The first example is nicotineinduced seizures. A seizure consisted of clonic-tonic activity and a loss of equilibrium, equivalent to four to five in the seizure scale of Franceschini et al. (2002). For both WT and L9'S mice, more animals displayed seizures at increasing nicotine doses (Fig. 1A), and the seizures began sooner after nicotine injection (Fig. $1 B$ ). However, these dose-response relationships were dramatically shifted to lower concentrations for the L9'S mice. All L9'S mice injected with $2 \mathrm{mg} / \mathrm{kg}$ nicotine displayed seizures, whereas a concentration of $10 \mathrm{mg} / \mathrm{kg}$ was required to elicit seizures in $100 \%$ of WT animals. In general, WT mice with seizures displayed a more complex behavioral pattern than L9'S mice, which included circling, free running, and jumping. The nicotinic receptor antagonist mecamylamine completely blocked seizures induced by nicotine $(1.5 \mathrm{mg} / \mathrm{kg}$ ) in all L9'S animals tested (Fig. $1 F$ ).

Spande et al. (1992) described Straub tail (a nearly vertical tail) as a response to nicotinic agonists in studies of epibatidine. Straub tail is the most sensitive nicotine effect we have found in L9'S mice (Fig. 1C,D): 65\% of L9'S mice injected with a nicotine concentration of $0.1 \mathrm{mg} / \mathrm{kg}$ displayed Straub tail, but none had seizures (Fig. $1 E$ ). In L9'S mice, seizures were always preceded by Straub tail. In WT mice, in contrast, no nicotine concentration was found to induce Straub tail only, but when Straub tail did occur, it was always during seizure. Mecamylamine blocked nic- 

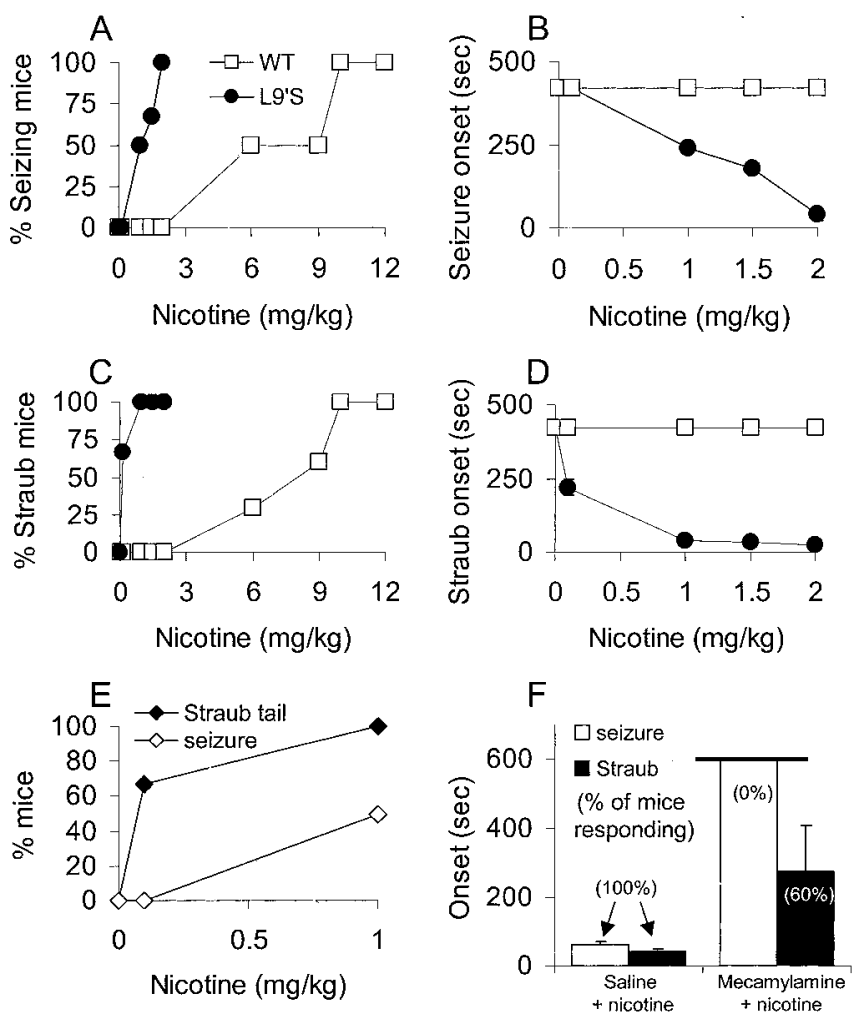

Figure 1. Nicotine induction of seizures and Straub tail in $\mathrm{L}^{\prime} \mathrm{S}$ and WT littermate mice. $A, B$, Animals received a single subcutaneous nicotine injection, and the percentage of mice that showed seizures and the time of seizure onset were recorded. C, D, Animals used in $A$ were also scored for Straub tail. The percentage of mice responding and the time of Straub onset were recorded. Continuous video recording of the mice after nicotine injection lasted $430 \mathrm{sec}$. Animals that did not respond during video recording time were assigned a 430 sec onset time. Each data point from the onset graphs is the mean $\pm \mathrm{SE} ; n=6$. $E$, Comparison of percentage responses for Straub tail and seizure in $\mathrm{L}^{\prime}$ 'S mice, showing the higher sensitivity to Straub tail. $F$, L9'S animals received either a saline or a $2 \mathrm{mg} / \mathrm{kg}$ intraperitoneal mecamylamine injection, followed by a $1.5 \mathrm{mg} / \mathrm{kg}$ subcutaneous nicotine injection $5 \mathrm{~min}$ later. Time to seizure and Straub tail were recorded. Each bar represents mean $\pm \mathrm{SE} ; n=5$. The horizontal line indicates the maximum observation period $(600 \mathrm{sec})$. None of the mecamylamine plus nicotine-treated mice had seizures, and $60 \%$ displayed Straub tail during this period.

otine $(1.5 \mathrm{mg} / \mathrm{kg})$-induced Straub tail in two of five L9'S mice tested and, in the remaining three animals, delayed the onset of Straub tail by sixfold, compared with animals that received nicotine alone (Fig. $1 F)$.

In addition to nicotine hypersensitivity, L9'S mice were also more sensitive than WT mice to epibatidine (Fig. 2A). Epibatidine induced seizures and Straub tail in L9'S animals at concentrations $(\leq 10 \mu \mathrm{g} / \mathrm{kg})$ that caused no noticeable effects in WT animals. Epibatidine seizures in L9'S animals were always preceded by Straub tail. For epibatidine, as for nicotine, Straub tail was the more sensitive assay: at a dose of $2 \mu \mathrm{g} / \mathrm{kg}$, most L9'S mice displayed Straub tail but none had seizures.

Although L9'S mice were hypersensitive to nicotine and epibatidine, L9'S and WT mice showed similar sensitivity to the $\mathrm{GABA}_{\mathrm{A}}$ receptor blocker bicuculline (Fig. $2 \mathrm{~B}$ ). Bicuculline induced seizures and Straub tail in both L9'S and WT mice in a dose-dependent manner. Both L9'S and WT animals had very severe, prolonged, and in some cases lethal bicuculline-induced seizures.

We also studied Straub tail and seizure responses to galanthamine and tacrine, two drugs thought to operate on cholinergic systems (Fig. 2C,D). L9'S mice displayed Straub tail responses at

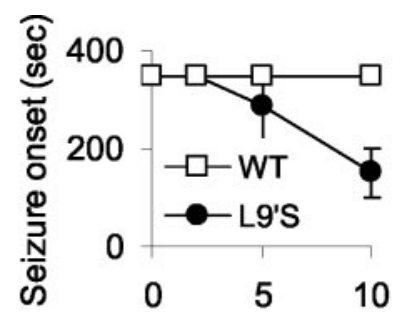

A Epibatidine $(\mu \mathrm{g} / \mathrm{kg})$
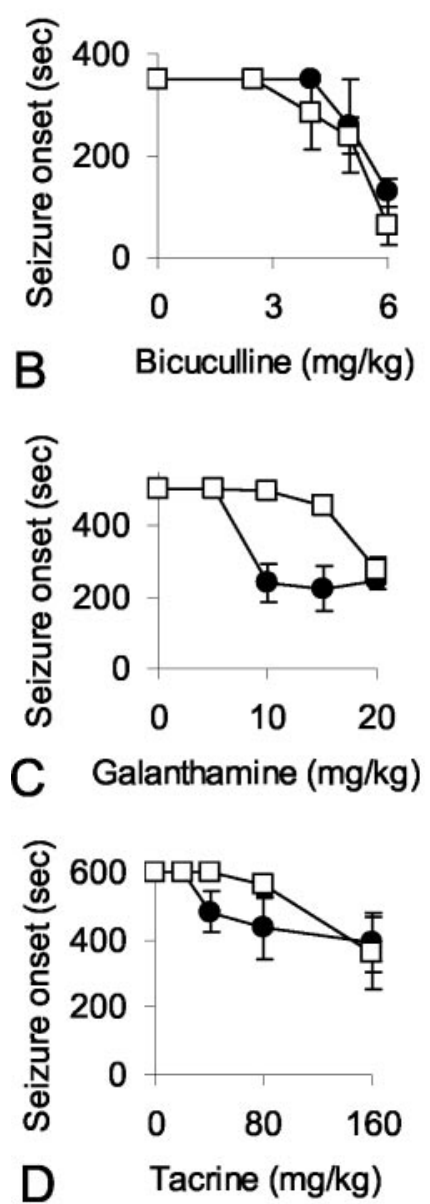

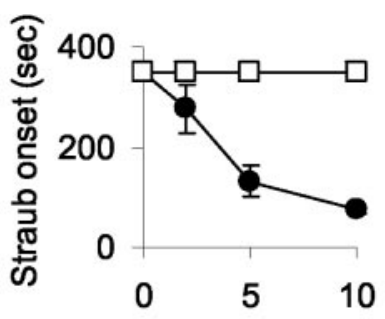

Epibatidine $(\mu \mathrm{g} / \mathrm{kg})$

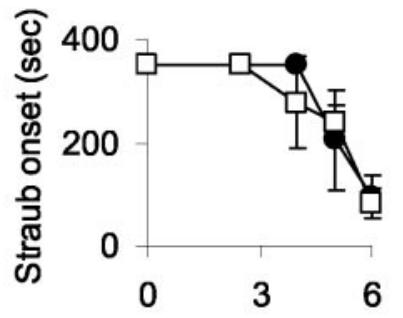

Bicuculline $(\mathrm{mg} / \mathrm{kg})$

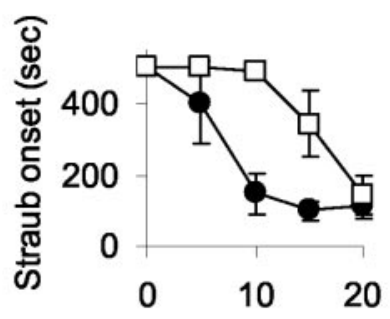

Galanthamine $(\mathrm{mg} / \mathrm{kg})$

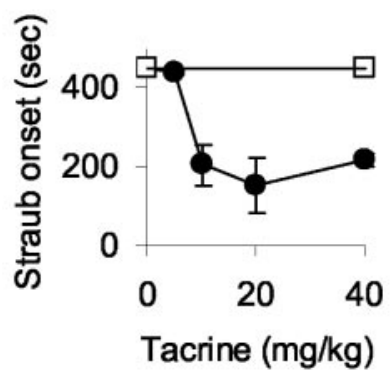

Figure 2. Epibatidine, bicuculline, galanthamine, or tacrine induction of seizures (left panels) and Straub tail (right panels) in L9'S and WT littermate mice. A, Animals received a single subcutaneous epibatidine injection, and the times of seizure and/or Straub tail onset were recorded. $B$, Animals received a single bicuculline intraperitoneal injection, and the times of seizure and/or Straub tail onset were recorded. C, Animals received a single intraperitoneal galanthamine injection, and the times of seizure and/or Straub tail onset were recorded. $D$ Animals received a single subcutaneous tacrine injection, and the times of seizure and/or Straub tail onset were recorded. Mice with seizures lasting $\geq 5$ min were killed. Animals injected with epibatidine or bicuculline that did not respond during video-recording time were assigned a 350 sec onset time. Animals injected with galanthamine that did not respond were assigned a 450 sec onset time, and nonresponding mice treated with tacrine were assigned a 600 sec onset time. Each data point is the mean $\pm \mathrm{SE} ; n=4$ or 6 . There was a significant difference in seizure onset between WT and L9'S mice injected with 40 or $80 \mathrm{mg} / \mathrm{kg}$ tacrine $(p<0.05)$.

significantly lower concentrations than WT mice for both drugs. In fact, there were no Straub tail responses in WT mice at any concentration up to $160 \mathrm{mg} / \mathrm{kg}$ tacrine, the highest concentration tested; but $50 \%$ of L9'S mice responded with Straub at $\sim 10 \mathrm{mg} /$ $\mathrm{kg}$. L9'S mice were also hypersensitive to galanthamine- or tacrine-induced seizures; galanthamine induced seizures at approximately fourfold lower concentrations in the mutant than 


\section{A}

\section{Morphine $10 \mathrm{mg} / \mathrm{kg}$}

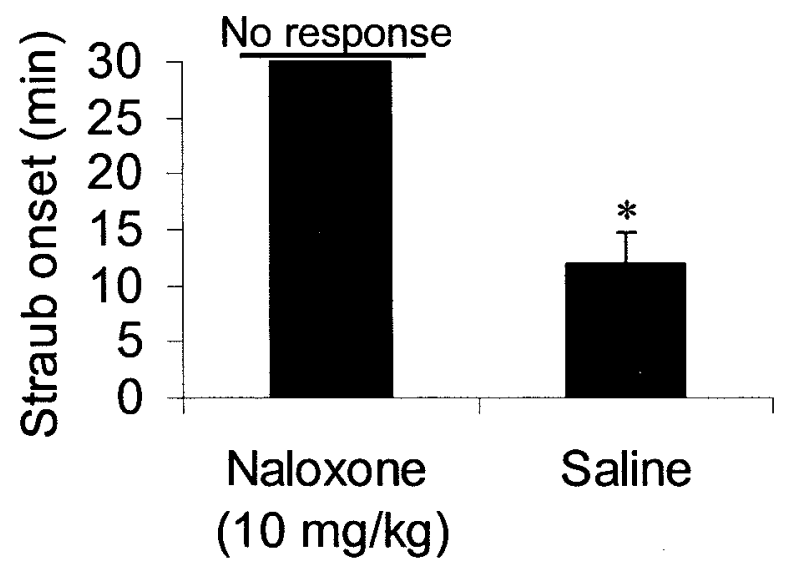

\section{B Nicotine $(0.2 \mathrm{mg} / \mathrm{kg})$}

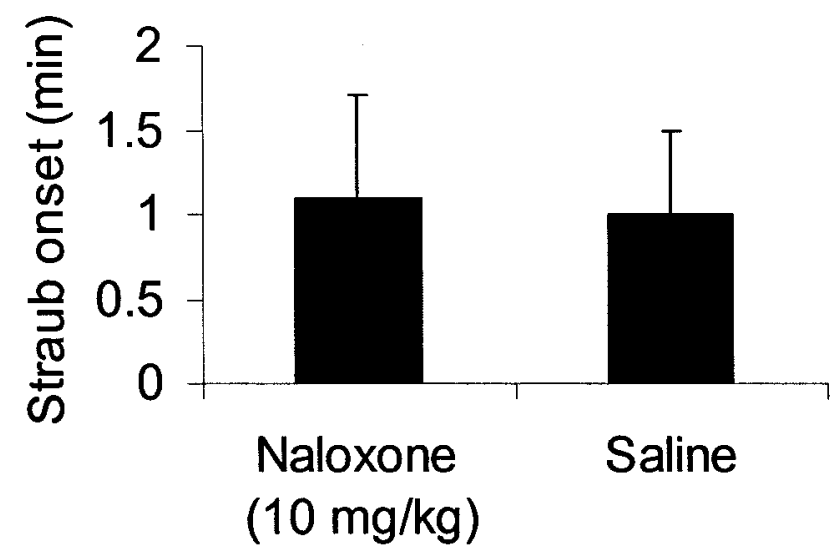

Figure 3. Morphine and nicotine induction of Straub tail in L9'S mice. Animals received a subcutaneous morphine or nicotine injection $10 \mathrm{~min}$ after an intraperitoneal naloxone or saline injection. Morphine and nicotine induced Straub tail in L9'S mice. $A$, Morphine Straub induction was blocked by the $\mu$-opioid receptor antagonist naloxone. ${ }^{*} p<0.01$ when comparing salineand naloxone-treated groups ( $t$ test; $n=4$ ). $B$, Nicotine-induced Straub was unaffected by naloxone. Experiments lasted $30 \mathrm{~min}$, and animals not responding within that time received a 30 min onset score. Each bar represents mean $\pm \mathrm{SE} ; n=4$.

WT mice (Fig. 2C). Mice were less sensitive to tacrine effects than to other drugs tested: tacrine induced seizures in WT mice only at doses $\geq 80 \mathrm{mg} / \mathrm{kg}$ and only after $>400 \mathrm{sec}$; and we noted that tacrine-injected mice displayed seizures only after spontaneous or handling-initiated movements. Nonetheless, the data show that L9'S mice were significantly more sensitive than WT mice to tacrine when handled similarly $(p<0.05$ at 40 and $80 \mathrm{mg} / \mathrm{kg})$ (Fig. 2C).

Straub tail is often measured as a response to opioids. Morphine did induce Straub tail in L9'S mutant mice (Fig. 3A). However, there were clear differences in the characteristics of Straub tail induced by morphine and nicotine. Morphine-induced Straub tail began, on average, 10 min after morphine injection, in contrast to the delay of $\sim 1$ min after nicotine injection (Fig. $3 B$ ). Furthermore, morphine-induced Straub tail, but not nicotineinduced Straub tail, was completely blocked by the $\mu$-opioid receptor antagonist naloxone.
In vivo electrophysiological recordings show hypersensitivity to nicotine

Field recordings from hippocampi of L9'S mice ( $n=6$ animals) revealed changes in the EEG trace after a seizure-inducing dose of $2 \mathrm{mg} / \mathrm{kg}$ nicotine (Fig. 4). Onset of behavioral seizure coincided in time with an increase in amplitude of the EEG trace (Fig. 4B). No consistent changes in EEG amplitude were observed in WT mice $(n=3)$ after $2 \mathrm{mg} / \mathrm{kg}$ nicotine injection, concentrations at which these mice displayed no behavioral seizures (Fig. 4A). Power spectra of the records in L9'S mice showed a large nicotine-induced increase in power density at theta frequencies $(\sim 7 \mathrm{~Hz})$. Four of the six L9'S mice displayed greater than or equal to threefold enhancement of theta rhythm power after nicotine injection (Fig. $4 B$ ). Also, the SD of the records increased markedly in most L9'S animals but not in WT animals (Fig. 4A). One L9'S animal displayed spike-wave hippocampal discharges.

We also recorded EEG traces in five WT mice after $10 \mathrm{mg} / \mathrm{kg}$ nicotine injection, which led to seizures in each animal (Fig. 4C). The signals in these WT nicotine-treated mice were much more complex than the sustained and increased EEG amplitude in L9'S mice at $2 \mathrm{mg} / \mathrm{kg}$. EEG traces of WT animals during seizure showed bursts of activity (3-6 sec). In most of these nicotinetreated WT animals, there were increases in power over the spectrum from 1 to $>20 \mathrm{~Hz}$ (Fig. 4C). Only one of these animals showed an increase in theta rhythm alone; two animals showed spike waves during seizures. During intervals between behavioral seizures, there was little or no abnormal electrical activity.

\section{Neuroanatomy}

Various brain structures including the frontal cortex, hippocampus, thalamus, and hindbrain were examined to determine whether the L9'S mutation caused gross anatomical abnormalities. In Nissl-stained sections (Fig. 5), layering appeared normal and all major cell groups were present.

Neurochemical studies: knock-in mice have fewer receptors, but many are hypersensitive

In this section, we explicitly refer to adult L9'S mice as L9'S heterozygotes. Figure $6 \mathrm{~A}$ shows $\left[{ }^{125} \mathrm{I}\right]$ epibatidine binding in adult mice thalamus preparations, and Figure $6 B$ shows $\left[{ }^{125} \mathrm{I}\right]$ epibatidine binding in fetal mice whole-brain preparations. Epibatidine saturation curves in preparations of adult mice thalamus show a decrease in epibatidine binding from $98.8 \mathrm{fmol} / \mathrm{mg}$ protein in WT mice to $64.1 \mathrm{fmol} / \mathrm{mg}$ protein in L9'S heterozygotes, with $K_{\mathrm{D}}$ values of $64.1 \mathrm{pM}$ and $69.8 \mathrm{pM}$, respectively. This $35 \%$ decrease in maximal binding, with indistinguishable $K_{\mathrm{D}}$ values, is presumably attributable entirely to decreased expression from the mutant allele, implying that the mutant allele has $\sim 70 \%$ less expression than the WT allele. The decreased expression is thought to occur not because of the point mutation but because of the $\sim 2 \mathrm{~kb}$ neomycin-resistance cassette in the intron downstream from exon 5 (Labarca et al., 2001). Decreased expression because of the presence of the neomycin cassette has been reported in other neo-intact mice (Wang et al., 1999; Single et al., 2000; Broide et al., 2002). It has been suggested that the neomycin cassette may interfere with splicing or other post-transcriptional events that would result in decreased protein expression (Balfour, 1994). Greater precision and confirmation of reduced receptor expression calls for measurements on homozygous L9'S mice. These mice die neonatally, preventing such experiments on adults. We therefore performed $\left[{ }^{125} \mathrm{I}\right]$ epibatidine binding experiments on fetal mouse brains (Fig. $6 B$ ), although only adults were used for the behavioral, pharmacological, and electrophysiolog- 

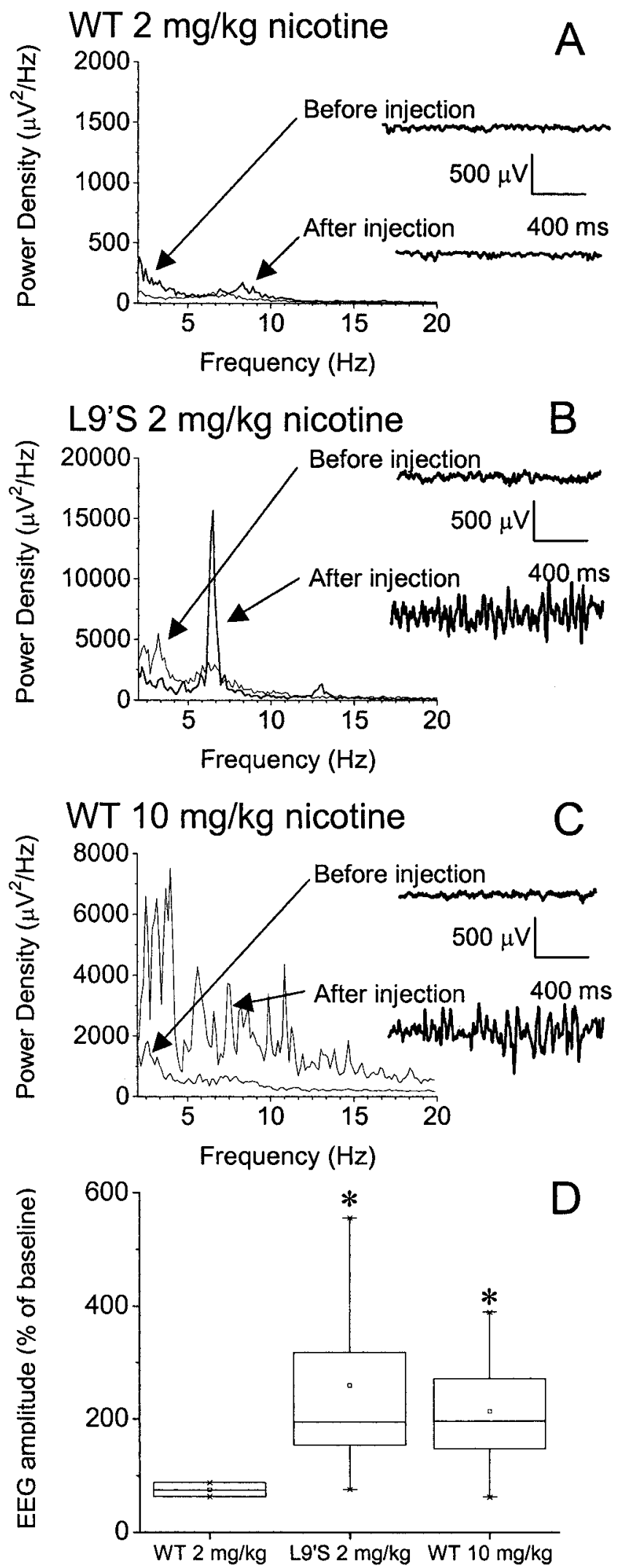

Figure 4. Traces from hippocampal field recordings and power spectrum analysis in WT $(A)$ and $L 9^{\prime} S(B)$ mice, respectively, before and after a $2 \mathrm{mg} / \mathrm{kg}$ nicotine injection. Raw traces and power spectra analysis reveal an increase in peak-to-peak signal and theta rhythm amplitude, respectively, during seizure in the $L 9$ 'S animal. C, A typical WT mouse, before and 10 min after a $10 \mathrm{mg} / \mathrm{kg}$ nicotine injection. Each power spectrum represents $1 \mathrm{~min}$ of continuous data. $D$, Box-plot graph showing a significant increase in the SD of $L 9^{\prime} S$ traces ( $n=6$ animals) injected

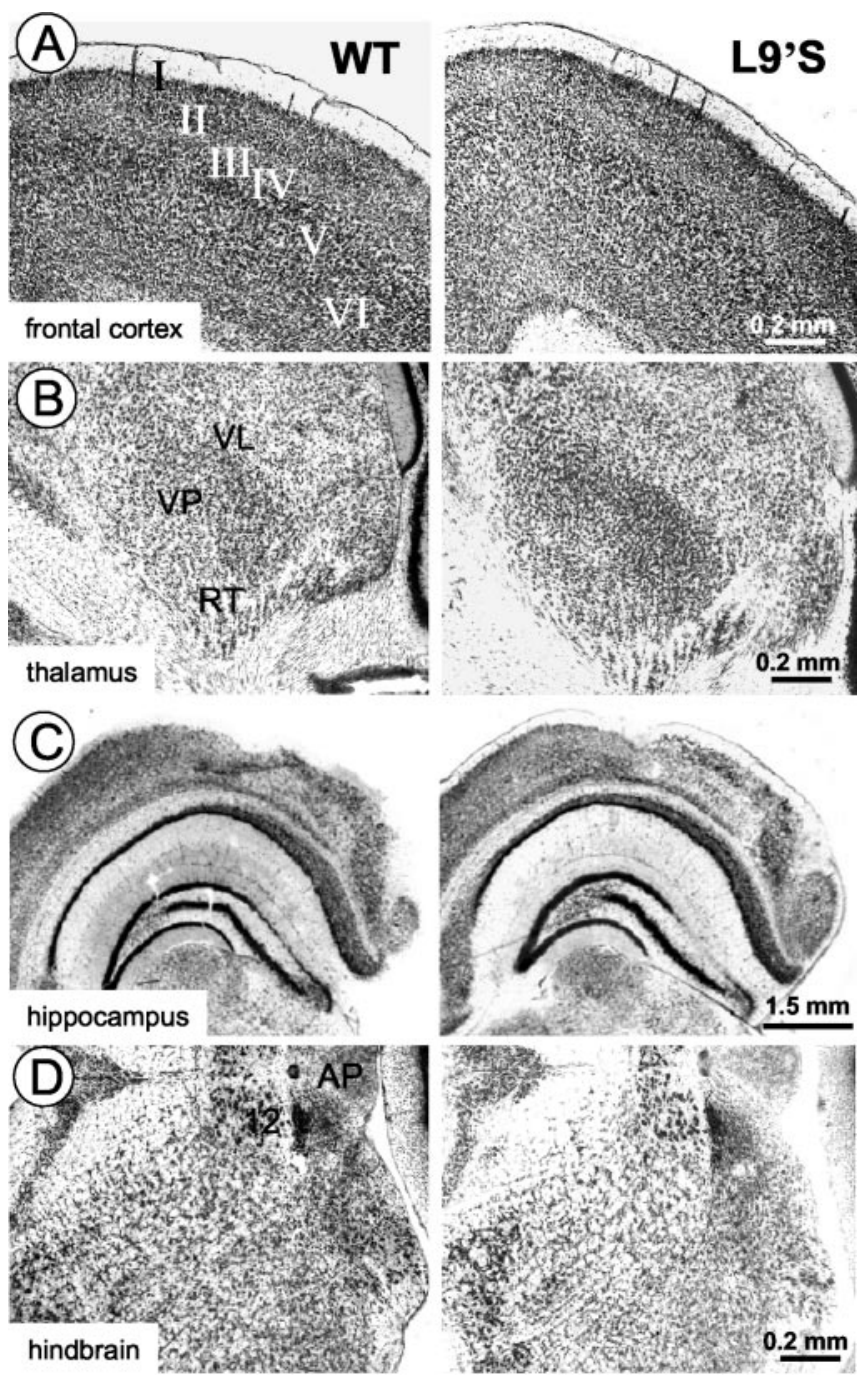

Figure 5. Nissl-stained coronal brain sections of WT (left panels) and L9'S (right panels) mice. $A$, Frontal cortex shown at the level of the primary motor cortex. Layers are labeled. $B$, Ventrolateral aspect of the thalamus. VL, Nucleus ventralis lateralis thalami; VP, nucleus ventralis posterior thalami; $R T$, nucleus reticularis. C, Hippocampus and adjacent secondary visual cortex. D, Dorsomedial aspect of the hindbrain, including area postrema (AP) and the hypoglossal nucleus (12)

ical experiments reported in this paper. There is a gene dosedependent decrease in total epibatidine binding from 75.7 $\mathrm{fmol} / \mathrm{mg}$ protein in WT mice to $51.3 \mathrm{fmol} / \mathrm{mg}$ protein in heterozygous L9'S fetal mice and to $23.4 \mathrm{fmol} / \mathrm{mg}$ protein in fetal mice homozygous for the mutation (and for the adjacent neo cassette). The apparent $K_{\mathrm{D}}$ values in fetal mice are unaffected by the mutation (20.7, 21.8, and $19.6 \mathrm{pm}$, respectively). Because equilibrium ligand-binding experiments with nicotinic receptors are dominated by binding to desensitized state(s), the unchanged affinity between WT and heterozygous L9'S mice may indicate that, although the open state occurs at a lower agonist concentration in the L9'S mutations, there is little change in the affinity for desensitized state(s). Cytisine-sensitive [ $\left.{ }^{125} \mathrm{I}\right]$ epibatidine binding provides an accurate measurement of $\alpha 4$-containing receptors

with $2 \mathrm{mg} / \mathrm{kg}$ nicotine or WT mice injected with $10 \mathrm{mg} / \mathrm{kg}$ nicotine $(n=5)$ compared with WT mice $(n=3)$ injected with $2 \mathrm{mg} / \mathrm{kg}$ nicotine $\left({ }^{*} p=0.05\right)$. There was no behavioral or electroencephalographic evidence of seizure in any wild-type mouse injected with nicotine $(2 \mathrm{mg} / \mathrm{kg})$. 
A
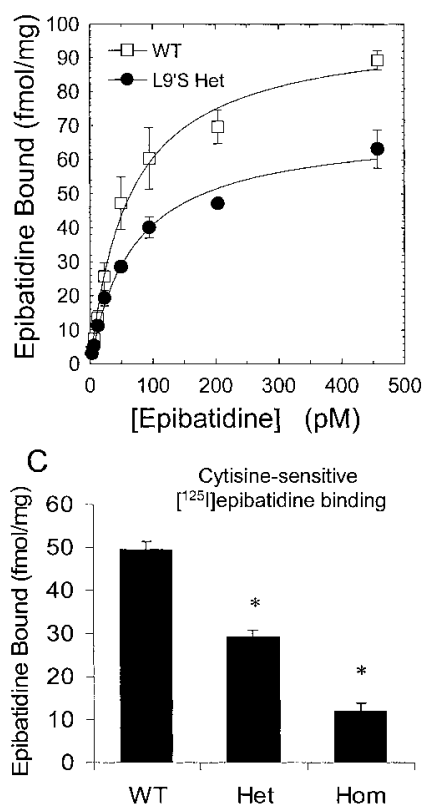

$\mathrm{B}$
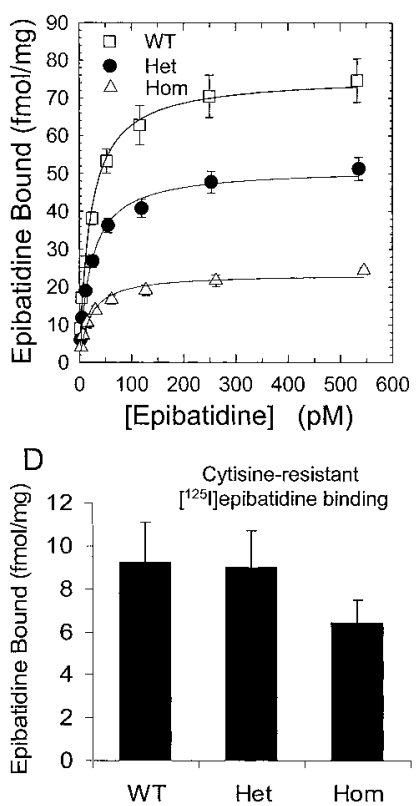

Figure 6. $\left[{ }^{125} \mid\right]$ Epibatidine binding to mouse brain membranes. $A$, Epibatidine binding in membranes prepared from adult WT and heterozygous (Het) L $9^{\prime}$ S brains. Each data point is the mean $\pm \mathrm{SE} ; n=4$. B, Epibatidine binding in membranes obtained from WT, heterozygous, and homozygous (Hom) embryonic brains. Each data point is the mean $\pm S E ; n=4$. C, D, Cytisinesensitive and cytisine-resistant epibatidine binding, respectively, in embryonic membranes. Each data point is the mean $\pm \mathrm{SE} ; n=4 ;{ }^{*} p<0.01$.

(Marks et al., 1998, 2000). Figure 6C shows cytisine-sensitive high-affinity epibatidine binding in fetal mice. The primary effect of the $\alpha 4$ L9'S mutation is a gene dose-dependent, significant reduction of the cytisine-sensitive component, from 47.7 to 29.1 to $12.3 \mathrm{fmol} / \mathrm{mg}$, with little effect on cytisine affinity $\left(F_{(2.9)}=\right.$ 246.19; $p<10^{-4}$ ). These data allow the conclusion that the neomycin-selection cassette reduces the expression of the mutated $\alpha 4$ subunit by $\sim 75 \%$ in fetal mice, similar to the value $(70 \%)$ calculated from the less precise experiments in heterozygote L9'S adults.

There is a small, insignificant decrease in the cytisine-resistant component between the WT to the L9'S homozygote (Fig. 6D). Low-affinity epibatidine binding sites displaced by cytisine were $12.9 \mathrm{fmol} / \mathrm{mg}$ in WT and $16.7 \mathrm{fmol} / \mathrm{mg}$ in heterozygote L9'S mice, several fold lower than the value for high-affinity epibatidine binding sites in WT mice.

We measured agonist-stimulated ${ }^{86} \mathrm{Rb}$ efflux in adult forebrain synaptosomes as a functional complement to the epibatidine binding (Fig. 7). Synaptosomes stimulated by increasing concentrations of acetylcholine (Fig. $7 A$ ) or nicotine (Fig. $7 B$ ) released increasing amounts of ${ }^{86} \mathrm{Rb}$. At higher agonist concentrations, synaptosomes obtained from L9'S mice had nearly twofold less rubidium efflux than WT mice after stimulation by either acetylcholine or nicotine, presumably because the mutant mice had fewer receptors. However, these differences were smaller at low concentrations. The ${ }^{86} \mathrm{Rb}$ efflux data were analyzed in terms of two saturable components. The high-affinity component (maximal flux, V1) accounted for a threefold to fourfold higher fraction of the efflux for the mutant mice than for WT mice. It should be understood that such an analysis is formal and cannot be readily related to agonist-receptor interactions on a millisecond time scale. Nonetheless, this analysis reveals that the mutant mice have a gain of function at low ACh and nicotine

\begin{tabular}{|l|l|l|l|}
\hline ACh & $\begin{array}{l}\mathrm{K} 1 \\
\mu \mathrm{M}\end{array}$ & $\begin{array}{l}\mathrm{K} 2 \\
\mu \mathrm{M}\end{array}$ & $\frac{\mathrm{V} 1}{\mathrm{~V} 2}$ \\
\hline $\mathrm{WT}$ & 1.5 & 57 & 0.7 \\
\hline Het & 1.8 & 100 & 2.0 \\
\hline
\end{tabular}

\begin{tabular}{|l|l|l|l|}
\hline Nic & $\begin{array}{l}\mathrm{K} 1 \\
\mu \mathrm{M}\end{array}$ & $\begin{array}{l}\mathrm{K} 2 \\
\mu \mathrm{M}\end{array}$ & $\frac{\mathrm{V} 1}{\mathrm{~V} 2}$ \\
\hline $\mathrm{WT}$ & 0.22 & 6.5 & 0.37 \\
\hline Het & 0.19 & 4.7 & 1.2 \\
\hline
\end{tabular}
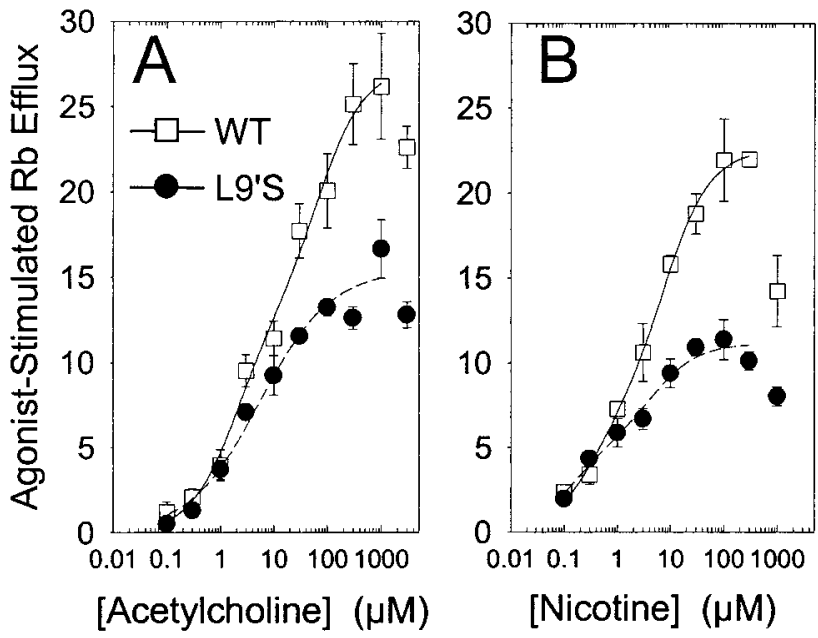

Figure 7. Rubidium efflux from synaptosomes prepared from adult WT ( $\square$ ) and heterozygous $\mathrm{L}^{\prime} S(\bigcirc)$ mouse brains. In each case, the curves represent fits to two components of efflux. The $\mathrm{EC}_{50}$ values $(K 1, K 2)$ and maximal efflux $(V 1, V 2)$ are given in the boxes. $A$, Acetylcholine induced rubidium efflux. Each data point is the mean $\pm \mathrm{SE} ; n=5$. $B$, Nicotine (Nic)-induced rubidium efflux. Each data point is the mean $\pm \mathrm{SE} ; n=5$. Het, Heterozygous.

concentrations, consistent with previous data from heterologous expression of the mutant receptor (Labarca et al., 2001) and with the behavioral and electrophysiological data presented above.

We also measured GABA release from the hippocampus of L9'S and WT mice (S. McCallum, M. J. Marks, and A. Collins, unpublished observations). The results showed no significant difference $(<10 \%)$ between the KCl- and ACh-stimulated GABA efflux between the two genotypes, suggesting that there are no differences in the proportion of GABAergic nerve terminals. The measurements of ACh-stimulated release lack the precision of the $\mathrm{Rb}$ release experiments but show no significant difference $(<20 \%)$ between $V_{\max }$ for the two genotypes. The $\mathrm{EC}_{50}$ for release $(1-3 \mu \mathrm{M})$, also showed no significant differences between the two genotypes.

\section{Discussion}

Molecular, cellular, and circuit basis of the seizure phenotype Our results show that, when the WT $\alpha 4 \mathrm{nAChR}$ subunit is replaced by the L9'S mutant, mice become dramatically (approximately eightfold) more sensitive to nicotine-induced seizures. An analogous hypersensitive nAChR knock-in mouse line, the $\alpha 7$ L9'T strain, shows a twofold increase in seizure sensitivity (Broide et al., 2002). The difference in seizure threshold between $\alpha 4$ and $\alpha 7$ mutant mice may be attributable in part to the fact that $\alpha 4 \beta 2$ receptors have much lower $\mathrm{EC}_{50}$ values $(\sim 100$-fold) for nicotine than homomeric $\alpha 7$ receptors. The nicotine-induced seizures in WT mice were more complex than those induced by lower nicotine levels in L9'S mice, as assessed by both behavioral criteria and by in vivo electrophysiology (Fig. 4), in keeping with the idea that WT nicotine-induced seizures arise from actions on additional nAChRs, probably including $\alpha 7$. The remote possibility that the $\sim 38 \%$ decrease in $\alpha 4$ subunits leads to unexpected compensatory changes at other nicotinic receptors, and in turn to the increased seizure sensitivity, is rendered unlikely by the fact 
(1) that changes in nicotine-induced seizures have not been reported for $\alpha 4$ knock-out mice, and (2) that $\alpha 4$ knock-out mice have an apparent increased sensitivity to bicuculline-induced seizures, in contrast to the present strain (Wong et al., 2002).

The L9'S mutation is not an identified ADNFLE mutation, but it is nonetheless informative. One ADNFLE mutation is at 10' and involves a Leu to Ser switch. The periodicity of mutational effects in the M2 region (Devillers-Thiery et al., 1992) is consistent with the hypothesis that an L9'S mutation could have physiological effects like an $\mathrm{S} 10^{\prime} \mathrm{L}$ mutation, and several studies indicate that the $S 10^{\prime} \mathrm{L}$ mutation has a gain-of-function character (Figl et al., 1998; Bertrand et al., 2002). We therefore propose that knock-in mouse strains bearing the ADNFLE mutations would, like the present strain, have increased susceptibility to seizures. If this hypothesis is verified, the proposed knock-in strains would serve as models for ADNFLE. We lack the equipment to observe these mice systematically for the presence of spontaneous seizures, but in the course of handling several hundreds of these mice for 4 years, including $24 \mathrm{hr}$ ambulation and activity monitoring, we have observed non-agonist-induced seizures only in tacrineinjected mice, which developed handling-induced seizures.

How do gain-of-function $\alpha 4 \mathrm{nAChRs}$ render a mouse hypersensitive to nicotine-induced seizures? CNS nAChRs may act primarily to modulate presynaptic neurotransmitter release, rather than to produce postsynaptic EPSCs (for review, see Wonnacott et al., 1990; Wonnacott, 1997; but see Ji et al., 2001). After stimulation by a nicotinic agonist, presynaptic $\mathrm{nAChR}$ responses could cause terminal depolarization, which in turn would facilitate either excitatory or inhibitory neurotransmitter release. There is good evidence that $\alpha 4$ receptors are primarily on GABAergic interneurons in the hippocampus and neocortex (Alkondon et al., 1997). Therefore activation of inhibitory terminals may result in enhanced GABA release, which, depending on the affected circuit, could inhibit primarily inhibitory pathways, resulting in net excitation. In another scenario, activation of inhibitory terminals and consequent GABA release could contribute to seizure induction by synchronization of glutamatergic neuronal activity (Mody, 1998). Measurements to date indicate only a relatively modest change in ACh-stimulated hippocampal GABA release in the L9'S mutants, suggesting that these changes may occur in only a subset of GABAergic interneurons.

In confirmation of these ideas, relatively low nicotine doses in awake L9'S animals did produce changes in field recordings obtained from chronically implanted electrodes. There was an increase in the peak-to-peak amplitude of EEG traces during behavioral seizures, primarily because of an increased theta rhythm. This observation is consistent with models of extracellular theta current generation in the cortex (Buzsaki, 2002). Cholinergic neurons in the medial septum projecting to pyramidal cells in the hippocampus provide "pacemaker" theta activity in the brain via both muscarinic and nicotinic pathways (Petsche et al., 1966). In our experiments, the presence of hypersensitive $\alpha 4$ nAChRs, stimulated by nicotine, apparently results both in seizure activity and in an enhanced hippocampal theta rhythm, presumably involving the septohippocampal pathway. Because we did not consistently observe spike-wave activity in the hippocampal recordings from the L9'S mice, our data do not allow the conclusion that the seizures originated in the hippocampus.

\section{Hypersensitivity to several nicotinic agonists but not to other drugs}

Several compounds were tested to determine the specificity of the L9'S mutation effects on seizure and Straub tail. First, nicotine- induced seizures in L9'S mice were completely blocked by the nicotinic antagonist mecamylamine. Second, epibatidine, a nicotinic receptor agonist (Badio and Daly, 1994), caused Straub tail and seizure in L9'S mice at much lower concentrations than in WT mice. In contrast, bicuculline, a GABA $\mathrm{A}_{\mathrm{A}}$ receptor blocker and commonly used proconvulsant, caused Straub tail and seizure at similar concentrations in L9'S and WT mice, suggesting that the mutation did not yield a generalized seizure phenotype. Therefore it is unlikely that hypersensitive $\alpha 4 \mathrm{nAChRs}$ are chronically activated, with a consequent tonic release of excitatory neurotransmitter, and thus maintaining a lowered seizure threshold. Specificity of the Straub tail response observed in L9'S mice was examined with morphine. Morphine-induced Straub tail onset was $\sim 10$ times longer than nicotine-induced Straub tail onset, and it was completely blocked by the $\mu$-opioid receptor blocker naloxone. Nicotine-induced Straub tail was significantly diminished by mecamylamine but unaffected by naloxone. Hence, in L9'S mice, Straub tail induction by morphine was very different from that obtained with nicotine. In sum, the behavioral effects observed in L9'S mice appear specific to the stimulation of $\alpha 4$ containing nicotinic circuits.

Tacrine and galanthamine are widely used to delay the cognitive decline associated with Alzheimer's disease and other dementias. Both of these drugs produced seizure and Straub effects at lower concentrations in L9'S mice than in WT mice (Fig. $2 C, D)$, consistent with the view that, by blocking cholinesterase, these drugs produce elevated ACh concentrations near ACh receptors. There is a approximately a fourfold range of galanthamine and tacrine concentrations in which these elevated ACh concentrations appear detectable by hypersensitive but not by normal receptors. Originally it was thought that both drugs were cholinesterase inhibitors and therefore counteracted the effects of cholinergic neuron death. Recent papers propose, however, that galanthamine, but not tacrine, is also a direct allosteric modulator of the $\alpha 4 \beta 2$ receptor (Samochocki et al., 2000; Maelicke et al., 2001). If so, one would expect a mouse with hypersensitive $\alpha 4 \beta 2$ receptors to show a dramatically enhanced behavioral effect of galanthamine compared with tacrine. The L9'S mice are indeed somewhat more sensitive to galanthamine than to tacrine (Fig. $2 C, D$ ), providing some evidence for the hypothesis (Fig. 2C,D). There are wide variations in the previously described effective doses for cognitive effects of tacrine and galanthamine in WT mice; the effective doses in the present study seem higher than the range for both drugs (Vincent et al., 1988; Sweeney et al., 1989; Pavone et al., 1998).

\section{Gene dosage effects on viability and hypersensitivity of L9'S strains}

We originally designed the L9'S strain to provide a severe gain of function (Labarca et al., 2001); unexpectedly, when both $\alpha 4$ subunits are mutant, the $\alpha 4\left(\mathrm{~L}^{\prime} \mathrm{S}\right) \beta 2$ receptor becomes so sensitive that it actually opens partially in response to choline at concentrations that are present in the CSF (Labarca et al., 2001). In both the neo-deleted heterozygote and the neo-intact homozygote (but not in the neo-intact heterozygote studied here), the resulting excitotoxic damage apparently kills many dopaminergic neurons, and the former two genotypes die soon after birth (Labarca et al., 2001).

The present study shows that the neo-intact allele is expressed at $\sim 25 \%$ of WT levels (Fig. 6). The decrease in high-affinity epibatidine binding occurs in the cytisine-sensitive but not in the cytisine-resistant fraction, thus indicating that changes in expression correspond primarily to $\alpha 4 \beta 2$ receptors rather than to other 


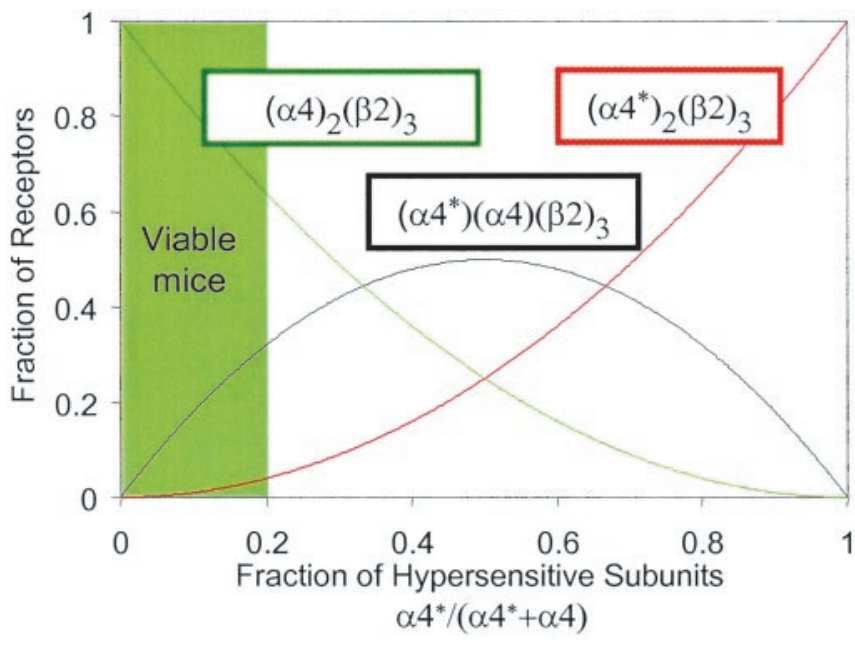

Figure 8. Expected types and proportions of $\mathrm{L} 9$ 'S and WT $\alpha 4 \beta 2$ receptors in $L 9$ 'S mice. The $\alpha 4 \mathrm{~L} 9^{\prime} \mathrm{S}$ subunit is abbreviated $\alpha 4^{*}$. The $x$-axis is the proportion of hypersensitive subunits, $x=$ $\alpha 4^{*} /\left(\alpha 4^{*}+\alpha 4\right)$, and runs from 0 to 1 . We assume that the complete multimeric receptor has the stoichiometry $(\alpha 4)_{2}(\beta 2)_{3}$, although the three non- $\alpha$ subunits may have a more complex identity. The proportion of receptors with two WT $\alpha 4$ subunits, $1-x^{2}$, is shown in green and decreases along the $x$-axis. The proportion of receptors with one mutant and one WT subunit, $x(I-x)$, is shown in black and peaks at $x=0.5$. The proportion of receptors with two mutated subunits, $x^{2}$, is shown in red and increases along the $x$-axis. The area inside the green rectangle represents the gene dosage of hypersensitive subunit that allows viable mice. This area extends from 0 to $x=0.2=0.25 /(1+0.25)$, representing full expression of the normal allele and $25 \%$ expression of the mutant allele, as found in the present study. The value $x=0.5$ would represent the lethal neo-deleted heterozygote, and $x=1$ would represent the lethal neo-deleted and neo-intact homozygotes (Labarca et al., 2001).

nicotinic receptors such as $\alpha 7, \alpha 3 \beta 2, \alpha 3 \beta 4$, or $\alpha 6 \beta 2 \beta 3$. The fact that there were no significant changes in epibatidine binding of the cytisine-resistant fraction also suggests that no major compensatory mechanisms at the level of nicotinic receptor expression took place.

Figure 8 presents our view of the relationships among gene dosage, receptor composition, and viability. In brief, only $20 \%$ of the $\alpha 4$ subunits are hypersensitive, and the total number of $\alpha 4$ subunits is only $\sim 63 \%$ of normal levels. These values lead to the conclusion that only $\sim 4 \%$ of the receptors have two $\alpha 4 \mathrm{~L} 9^{\prime} \mathrm{S}$ (denoted $\alpha 4^{\star}$ in Fig. 8) subunits, which are activated by choline. Presumably this small number of choline-activated subunits is consistent with viability. These receptors are also 30 -fold more sensitive than normal to either ACh or nicotine (Labarca et al., 2001). Some $32 \%$ of the receptors have one $\alpha 4 L \mathrm{~L}^{\prime} \mathrm{S}$ subunit and one WT subunit; previous data on the muscle nAChR suggest that these receptors have an intermediate level of hypersensitivity (Labarca et al., 1995), although this point has not been measured systematically. We do not know whether the profound agonistsensitive phenotypes of the present heterozygote L9'S mouse arise primarily from the $\sim 4 \%$ of receptors with extreme hypersensitivity or from the $\sim 32 \%$ with moderate hypersensitivity. Experiments with less drastically hypersensitive and more viable $\alpha 4$ receptor knock-in strains are now under way and may settle this point.

Incidentally, the neonatal lethality of the homozygous L9'S line is in contrast to the viability of the $\alpha 4$ knock-out mice (Marubio et al., 1999; Ross et al., 2000). This fact provides additional evidence that the presence of the hypersensitive mutated receptor rather than a decrease in receptor expression, which is complete in the case of the $\alpha 4$ knock-out, is responsible for the observed lethality.

\section{Conclusions}

These studies emphasize the utility of gain of function L9'S knock-in mice for examining the function of $\alpha 4$-containing nAChRs in the brain. Data to be reported elsewhere on these mice show the importance of the $\alpha 4$ subunit in mediating nicotine analgesia in supraspinal responses and the minimal $\alpha 4$ modulation of nociception in spinal reflex pathways. The increased sensitivity to agonist-induced seizures of the $\alpha 4 \mathrm{~L} 9^{\prime}$ S subunit may be relevant to the pathophysiology of ADNFLE caused by various mutations in the $\mathrm{M} 2$ domain of $\alpha 4$ and $\beta 2$ receptor subunits.

\section{References}

Alkondon M, Pereira EF, Barbosa CT, Albuquerque EX (1997) Neuronal nicotinic acetylcholine receptor activation modulates $\gamma$-aminobutyric acid release from CA1 neurons of rat hippocampal slices. J Pharmacol Exp Ther 283:1396-1411.

Badio B, Daly JW (1994) Epibatidine, a potent analgetic and nicotinic agonist. Mol Pharmacol 45:563-569.

Balfour DJ (1994) Neural mechanisms underlying nicotine dependence. Addiction 89:1419-1423.

Bertrand D, Picard F, Le Hellard S, Weiland S, Favre I, Phillips H, Bertrand S, Berkovic SF, Malafosse A, Mulley J (2002) How mutations in the nAChRs can cause ADNFLE epilepsy. Epilepsia 43 [Suppl 5]:112-122.

Brioni JD, Decker MW, Sullivan JP, Arneric SP (1997) The pharmacology of $(-)$-nicotine and novel cholinergic channel modulators. Adv Pharmacol 37:153-214.

Broide RS, Salas R, Ji D, Paylor R, Patrick JW, Dani JA, De Biasi M (2002) Increased sensitivity to nicotine-induced seizures in mice expressing the L250T $\alpha 7$ nicotinic acetylcholine receptor mutation. Mol Pharmacol 61:695-705.

Buzsaki G (2002) Theta oscillations in the hippocampus. Neuron 33:325-340.

Devillers-Thiery A, Galzi JL, Bertrand S, Changeux JP, Bertrand D (1992) Stratified organization of the nicotinic acetylcholine receptor channel. NeuroReport 3:1001-1004.

Figl A, Viseshakul N, Shafaee N, Forsayeth J, Cohen BN (1998) Two mutations linked to nocturnal frontal lobe epilepsy cause use-dependent potentiation of the nicotinic ACh response. J Physiol (Lond) 513:655-670.

Franceschini D, Paylor R, Broide R, Salas R, Bassetto L, Gotti C, De Biasi M (2002) Absence of $\alpha 7$-containing neuronal nicotinic acetylcholine receptors does not prevent nicotine-induced seizures. Brain Res Mol Brain Res 98:29-40.

Franklin KB, Paxinos G (1997) The mouse brain in stereotaxic coordinates. San Diego: Academic.

Ji D, Lape R, Dani JA (2001) Timing and location of nicotinic activity enhances or depresses hippocampal synaptic plasticity. Neuron 31:131-141.

Kuryatov A, Gerzanich V, Nelson M, Olale F, Lindstrom J (1997) Mutation causing autosomal dominant nocturnal frontal lobe epilepsy alters $\mathrm{Ca}^{2+}$ permeability, conductance, and gating of human $\alpha 4 \beta 2$ nicotinic acetylcholine receptors. J Neurosci 17:9035-9047.

Labarca C, Nowak MW, Zhang H, Tang L, Deshpande P, Lester HA (1995) Channel gating governed symmetrically by conserved leucine residues in the M2 domain of nicotinic receptors. Nature 376:514-516.

Labarca C, Schwarz J, Deshpande P, Schwarz S, Nowak MW, Fonck C, Nashmi R, Kofuji P, Dang H, Shi W, Fidan M, Khakh BS, Chen Z, Bowers BJ, Boulter J, Wehner JM, Lester HA (2001) Point mutant mice with hypersensitive $\alpha 4$ nicotinic receptors show dopaminergic deficits and increased anxiety. Proc Natl Acad Sci USA 98:2786-2791.

Maelicke A, Samochocki M, Jostock R, Fehrenbacher A, Ludwig J, Albuquerque EX, Zerlin M (2001) Allosteric sensitization of nicotinic receptors by galantamine, a new treatment strategy for Alzheimer's disease. Biol Psychiatry 49:279-288.

Marks MJ, Smith KW, Collins AC (1998) Differential agonist inhibition identifies multiple epibatidine binding sites in mouse brain. J Pharmacol Exp Ther 285:377-386.

Marks MJ, Stitzel JA, Grady SR, Picciotto MR, Changeux JP, Collins AC (2000) Nicotinic-agonist stimulated $\left[{ }^{86} \mathrm{Rb}\right]{ }^{+}$efflux and $\left[{ }^{3} \mathrm{H}\right]$ epibatidine binding of mice differing in $\beta 2$ genotype. Neuropharmacology 39:2632-2645.

Marubio LM, del Mar Arroyo-Jimenez M, Cordero-Erausquin M, Lena C, Le Novere N, de Kerchove d'Exaerde A, Huchet M, Damaj MI, Changeux JP 
(1999) Reduced antinociception in mice lacking neuronal nicotinic receptor subunits. Nature 398:805-810.

Mody I (1998) Interneurons and the ghost of the sea. Nat Neurosci 1:434-436

Pavone F, Capone F, Battaglia M, Sansone M (1998) Shuttle-box avoidance learning in mice: improvement by combined glucose and tacrine. Neurobiol Learn Mem 69:204-210.

Petsche H, Gogolak G, Stumpf C (1966) The projection of the cells of the pacemaker for the theta rhythm on the rabbit hippocampus. J Hirnforsch 8:129-136.

Revah F, Bertrand D, Galzi JL, Devillers-Theiry A, Mulle C (1991) Mutations in the channel domain alter desensitization of a neuronal nicotinic receptor. Nature 353:846-849.

Ross SA, Wong JY, Clifford JJ, Kinsella A, Massalas JS, Horne MK, Scheffer IE, Kola I, Waddington JL, Berkovic SF, Drago J (2000) Phenotypic characterization of an $\alpha 4$ neuronal nicotinic acetylcholine receptor subunit knock-out mouse. J Neurosci 20:6431-6441.

Samochocki M, Zerlin M, Jostock R, Groot Kormelink PJ, Luyten WH, Albuquerque EX, Maelicke A (2000) Galantamine is an allosterically potentiating ligand of the human $\alpha 4 / \beta 2 \mathrm{nAChR}$. Acta Neurol Scand Suppl 176:68-73

Single FN, Rozov A, Burnashev N, Zimmermann F, Hanley DF, Forrest D, Curran T, Jensen V, Hvalby O, Sprengel R, Seeburg PH (2000) Dysfunctions in mice by NMDA receptor point mutations NR1(N598Q) and NR1(N598R). J Neurosci 20:2558-2566.

Spande TF, Garraffo HF, Edwards MW, Yeh HJ, Pannell L, Daly JW (1992) Epibatidine: a novel (chloropyridyl)azabicycloheptane with potent anal- gesic activity from an Ecuadorian poison frog. J Am Chem Soc 114:3475-3478.

Sutor B, Zolles G (2001) Neuronal nicotinic acetylcholine receptors and autosomal dominant nocturnal frontal lobe epilepsy: a critical review. Pflügers Arch 442:642-651.

Sweeney JE, Puttfarcken PS, Coyle JT (1989) Galanthamine, an acetylcholinesterase inhibitor: a time course of the effects on performance and neurochemical parameters in mice. Pharmacol Biochem Behav 34:129-137.

Vincent GP, Pietrusiak N, Rummenik L, Sepinwall J (1988) The effects of galanthamine, an acetylcholinesterase inhibitor, on learning and memory in mice and monkeys. Soc Neurosci Abstr 14:58.

Wada E, Wada K, Boulter J, Deneris E, Heinemann S, Patrick J, Swanson LW (1989) Distribution of $\alpha 2, \alpha 3, \alpha 4$, and $\beta 2$ neuronal nicotinic receptor subunit mRNAs in the central nervous system: a hybridization histochemical study in the rat. J Comp Neurol 284:314-335.

Wang Y, Spatz MK, Kannan K, Hayk H, Avivi A, Gorivodsky M, Pines M, Yayon A, Lonai P, Givol D (1999) A mouse model for achondroplasia produced by targeting fibroblast growth factor receptor 3. Proc Natl Acad Sci USA 96:4455-4460.

Wong YF, Ross SA, McColl C, Massalas JS, Powney E, Finkelstein DI, Clark M, Horne MK, Berkovic SF, Drago J (2002) Proconvulsant-induced seizures in $\alpha 4$ nicotinic acetylcholine receptor subunit knockout mice. Neuropharmacology 43:55-64.

Wonnacott S (1997) Presynaptic nicotinic ACh receptors. Trends Neurosci 20:92-98.

Wonnacott S, Drasdo A, Sanderson E, Rowell P (1990) Presynaptic nicotinic receptors and the modulation of transmitter release. Ciba Found Symp 152:87-105. 